\title{
Designing for Elders: Exploring the Complexity of Relationships in Later Life
}

\author{
Siân E. Lindley \\ Microsoft Research Cambridge \\ $7 \mathrm{JJ}$ Thomson Avenue \\ Cambridge, CB3 OFB, UK \\ +44 (0) 1223479881 \\ v-silind@microsoft.com
}

\author{
Richard Harper \\ Microsoft Research Cambridge \\ $7 \mathrm{JJ}$ Thomson Avenue \\ Cambridge, CB3 OFB, UK \\ +44 (0) 1223479824 \\ r.harper@microsoft.com
}

\author{
Abigail Sellen \\ Microsoft Research Cambridge \\ $7 \mathrm{JJ}$ Thomson Avenue \\ Cambridge, CB3 OFB, UK \\ +44 (0) 1223479825 \\ asellen@microsoft.com
}

\begin{abstract}
We present a review of literature from the fields of gerontology, HCI and human factors, which focus on the nature of family and peer relationships in old age. We find both simplistic, prevailing models of what it means to be old, as well as deeper insights which often belie these models. In addition, we discover that new technologies are often also based on quite simple assumptions, but that their deployment points to a more complex reality. This paper considers a number of perspectives on relationships in later life, critiques the assumptions underscoring them, and presents an alternative view which we believe is more in line with the perspective of elderly people themselves. We end by discussing what this means in terms of designing new technologies for older people.
\end{abstract}

\section{Categories and Subject Descriptors}

H.5.0 [Information Systems]: Information Interfaces and Presentation (e.g., HCI) - General.

\section{General Terms}

Design, Human Factors.

\section{Keywords}

Elder, senior, old age, gerontology, reciprocity, asymmetry, autonomy, reassurance, roles, intimacy, engagement, play, family, intergenerational relationships.

\section{INTRODUCTION}

The aim of this paper is to explore how social relationships involving older people are characterised in the gerontology literature as well as in the fields of Human-Computer Interaction (HCI) and human factors. Technologies for elders are often built on the back of assumptions and theories (sometimes implicit) about their social connections: elders are sometimes presented as a socially isolated group that need to bolster connections with family, in other instances as a group that could benefit from being monitored by others, and in yet other cases as a group who have a special role to play in the lives of their grandchildren. Yet the deployment of technologies to support and enable these practices reveals insights into the social relationships in question that sometimes run counter to these theories and assumptions. Unfortunately, these findings

(c) The Author 2008

Published by the British Computer Society tend to be isolated, dotted throughout the HCI and human factors literature, rarely having an impact in the field of gerontology and most often not feeding into design iteration either. In the gerontology literature too there are papers that try to correct some of the assumptions and theories that are too readily deployed, but again this literature does not seem to feed into attempts to design for older people in any effective way.

Accordingly, this paper offers a sketch of how elderly people are understood from these different existing perspectives with a view to achieving the integration we think desirable. First, it will report on the view from gerontology, where the relationships the elderly have with their families, friends and peer groups is the primary concern. The second is from the perspective of human factors and $\mathrm{HCI}$, where the concern is to seek ways of allowing older people to continue their engagement with community and with family through the use of interactive technologies. A review of the work in these disciplines leads us to the conclusion that, irrespective of the merits of these views to date, when it comes to design, it is better to focus on the ways in which older people themselves approach their relationships with families and friends, the problems of continuity and commitment at work, and the values of interactive systems in domestic and private space.

For example, the suggestion that older people look after young children so that those same children will look after them in turn (when the old have become very old), what one might call the 'reciprocity thesis', will be shown to be contradicted by the strong resistance older people show to efforts by the young to cosset them later in life. Older people, sometimes irrespective of their evident physical and mental decline, can view the exercise of familial obligation as an assault on their dignity and moral worth. They often resist family assistance for this very reason. This is not to say that older people are unaware of the idea of reciprocity. In fact, to the contrary, it is one they know all too well. It is their orientation to that concept that is at issue.

Similarly the idea of symmetry in communicative practice is one that we find fails to stand up to close scrutiny. Yet this is one of the common threads in HCI research, holding that older people might feel more engaged with the world at large and their families in particular if they have a more equal and engaged role in communication with those they care about. We will suggest that this is a view that many older people reject, especially when it comes to family life. In contrast, many older people delight in asymmetry. For example, they are happy to learn about, watch and monitor their younger relations, but do not delight in those younger relations looking at them. As another, they may want to do more to help their families, but do not necessarily want their families doing more to help them.

The shift away from existing models and towards the views and orientations of older people themselves does not restrict design, 
however. Rather, we would claim it provides a rich basis for design imagination. Though symmetry, reciprocity, the idea of self-worth, and so forth, might be more complex and more delicately oriented to by older people than models within HCI would imply, an understanding of these complexities and orientations does point the way forward. It is the purpose of this paper to explain how this is so.

More particularly, the paper is organised as follows. First we deal with some definitional matters. Being old is more complex than the number of birthdays might suggest; it is also a state of mind, a social status and a societal view. We will also discuss the fact that whatever being old is, it is also a concept bound to human relations, especially familial. We will then review the literature, beginning with psychology and sociology and, in particular, their common subfield: gerontology. Here we will describe the kinds of models and ideas which dominate, such as that of reciprocity.

We then turn to the areas of $\mathrm{HCI}$ and human factors, and report how much of this research looks at helping older people to retain their level of engagement with the world, despite their functional decline. Systems are reported that are designed to assist older people, that monitor them or that act as agents for them in various ways. Others aim to strengthen communicative bonds between older people, their families and their peers. The insights in this literature are derived mainly when such systems are deployed. Here, for example, we will see that the elderly use communication in families in an asymmetric way, desiring to look but not to be looked at, and yet prefer symmetry with their social peers. The paper then concludes with a discussion of how a new way of looking at the elderly suggests different ways forward for the design of future technologies.

\subsection{Defining 'Old Age'}

Before we explore the literature relating to older people, we should define who it is that we are referring to. It is not quite as obvious as it might seem. Much of the recent interest in designing for elders has been motivated by the idea that the world's population is 'ageing'. Within the UK, for example, a third of the population is projected to be aged 55 or over by $2025^{1}$. Implicit in the notion of the ageing society is the idea that 'old age' can be defined, and that people who are experiencing old age form a recognisable group. However, there are a number of ways of thinking about what old age actually means, and how it can be identified.

Ageing can be understood as a biological process, as a stage within the life cycle, or in chronological terms. The former is rather difficult to operationalise for the purposes of research, unless looking at specific groups (e.g., those experiencing a particular type of cognitive decline). The second approach does find some space in the literature, especially within the field of gerontology, with elders sometimes being denoted as people in the 'third age'. This refers to Laslett's [37] third life stage of independent post-work (the first two stages being socialisation and work/child-rearing). Most frequently however, researchers take the approach of using a chronological cut-off point to determine who is to be defined as old, which in some cases incorporates 'older' people who are as young as 50 .

An alternative way of thinking about how old age can be defined is to explore how older people approach the issue. In an ethnographic study of the UK village of Dodworth, Degnen [16] examined how elders themselves construct what it means

\footnotetext{
${ }^{1}$ Data from the Office for National Statistics and Government Actuary's Department (2003 projections), source: http://news.bbc.co.uk/2/hi/uk_news/4012797.stm
}

to be 'old'. She noted that for the people in question, a distinction was drawn between normal ageing, which could comprise a number of indicators of physical decline such as arthritis, diabetes and blanks in memory, and real old age, which was signified by sharp declines in mental acuity and social comport. In describing a member of the community who was thought of as old, Degnen says:

"Mrs Atherton is perceived as old because she is disruptive, because she is temporally confused, [..] because she repeats herself, and because she forgets answers she has been given to questions and asks them again." (p. 75)

Because of the negative connotations associated with being old, elders rarely perceive themselves in this way, preferring to see themselves as 'getting on' rather than 'getting past it'. Therefore when defining what old age is, it is worth emphasising that there are large numbers of people who, while identified as belonging to the 'aged' fraction of our ageing societies, remain autonomous and do not consider themselves to be old.

Nevertheless, these individuals form a group that have certain characteristics in common. They are largely retired or semiretired, and are therefore likely to have undergone a notable life shift in the move from employment (or from living with a partner in employment). Further life changes may also have occurred or at least be on the horizon, including moves to downsize the family home and perhaps enter sheltered accommodation. As well as broadly sharing various life circumstances, elders as a cohort may have certain attitudes towards the notion of family, friendship and their associated roles. These also mark them out as a group with unique design requirements, and perhaps do so more strongly than the potential for their experiencing physical or cognitive decline.

\subsection{Relationships in Later Life}

Relationships with others, and particularly with kin, form the crossover point in the different fields of research to be explored in this paper. An overview of the gerontology literature was garnered by browsing recent issues of the key journals and then deriving keywords from papers of interest to enable a more comprehensive search. Journals included the Journal of Gerontology, the Journal of Aging Studies and Research on Aging. The HCI literature was examined through keyword searches of the ACM Digital Library and journals such as Human-Computer Interaction and Interacting with Computers. While the search of the gerontology literature was focused on papers relating to relationships, the HCI and human factors literatures were searched for papers relating to older people in general, before concentrating on relationships in later life.

An exploration of relationships in both fields motivates this review for two reasons. To begin with, many technologies designed for elders are in some way related to relationships, especially family relationships. From technologies that monitor patterns of behaviour to those that support two-way communications, new designs are often motivated by hypotheses about the nature of relationships, and through their deployment we can learn something of the strength of these assumptions. Secondly, relationships are known to be an important contributing factor to wellbeing in old age. Good social relationships were shown to be a principal contributing factor to quality of life in a large survey of British people aged 65 and over [24]. Similarly, deeper explorations of elders' lay definitions of quality of life have suggested that family in particular is significant. For example, interviews with older people [10] have suggested that 'access to significant relations' is one of four important factors contributing to quality of life. This is defined as involving the continuance of close bonds with 
others, resulting in a feeling of maintained self. However, the interviews also highlighted the mixed nature of familial bonds. Involvement with family can bring about feelings of togetherness, but family ties can also incorporate a sense of obligation that may bring a negative slant to relationships. Furthermore, while elders wish to partake in the lives of their adult children, they do not want to become invasive. Therefore, the notion of participation without intrusion is crucial.

The above underlines the importance of relatives to older people, while pointing to the complexity of family ties. Of course this is not only true for elders; kin relationships differ from those with peers in that they are likely to incorporate stronger elements of obligation at all stages in life. The purpose of this review is to highlight a number of themes that are recognised as characterising and influencing relationships within the gerontology literature, and balance them with attempts to design for elders in HCI.

\section{THEMES FROM GERONTOLOGY}

Popular conceptions of the elderly often see them depicted as an isolated and lonely group, in need of reinforced connections with family and lacking of friends. It is certainly true that as people age, they lose an increasing number of social contacts to illness and mortality, and with increasing frailty, opportunities for meeting new people or socialising with existing contacts become restricted. It is unsurprising then, that social networks decrease in size with increasing age [e.g., 39].

Perhaps more unexpected are findings showing that the number of close relationships within social networks remain stable until very old age [18], and that people become more positive about their social relationships as they grow older [13]. This has led some researchers to argue that much of the decrease in social network size is due to an active process of selective pruning rather than an inability to maintain contact. Carstensen and colleagues [e.g., 12, 13] have suggested that as people age, they prefer to invest in relationships that are emotionally rewarding and significant to them, and become less inclined to indulge in those that are no longer seen as consequential. This shifting attitude towards relationships is due to a change in motivation towards the end of life; instead of being driven to acquire new knowledge about the self and the social world, older people are motivated to derive emotional meaning from life, to establish intimacy and to verify the self.

This suggests that a shrinking network should not be cause for concern, so long as it has the potential to support fulfilling interactions with significant others. Indeed, research has shown that loneliness is not prevalent amongst the elderly, with recent statistics suggesting that only $7 \%$ of older people consider themselves to be often or always lonely [53]. These researchers also note that a distinction needs to be drawn between solitude and loneliness, with the experience of loneliness being a subjective state as much as the consequence of a lack of contact with others. Furthermore, it seems obvious that the nature of the contact is more important than the existence of contact per se. The idea that different types of contact have different effects on quality of life can be clearly illustrated using a couple of seemingly counterintuitive examples from the literature. In a study of cultural differences, van Tilburg et al. [52] found that Italian elders, who tend to live with their families, reported higher levels of loneliness and less social integration than Dutch elders, who tend to live alone. Similarly, an investigation of network diversity by Fiori et al. [20] showed that for elders with networks that are restricted to either friends or family, friendship was more beneficial for mental health.

At first it seems surprising that links with family in later life may not necessarily be as valuable as those with friends, especially in light of the argument that close relationships are of most significance at this stage in the life course. However, there are a number of clear differences between peer relationships and those with kin, and in particular the norms of responsibility and social propriety associated with each. Indeed, our reading of the literature suggests that one can separate out these differences into a number of basic themes: reciprocity and asymmetry, autonomy and dignity, and negotiated responsibilities. It is to these we now turn.

\subsection{Reciprocity and Asymmetry}

Reciprocity has been long recognised as a norm that underpins social relationships (e.g. [26]), and its existence has been suggested to have positive effects on parent-child affection and on rates of future intergenerational interaction [7]. Of course, family relationships, especially between parent and child, are typically asymmetrical when viewed at any point in time. Parents are expected to care for their young children, and when those parents become elderly the situation might be expected to reverse. But many researchers have argued that the provision of support balances out over time, thus meeting expectations of reciprocity. For example, Antonucci [2] has proposed that through care of their children, parents build up a 'support bank', which they then tap into in later life.

There is much evidence against this hypothesis however. For example, it is known that older parents continue to offer a good deal of support to their adult children, as well as to their grandchildren. Grandparents are often involved with childcare and elders are known to undertake activities such as homemaintenance for their children, the type of work that one might imagine their offspring would be doing for them. Grandparents also continue to provide a good deal of financial assistance to their adult children and grandchildren in later life [e.g., 30].

Through an analysis of data derived from the German Ageing Survey, Hoff [30] has explored whether financial transfers to family members can be understood as a way of reciprocating aid. Grandparents were asked whether they had given or received financial support or gifts to their children and grandchildren, and also whether they had given help or had received assistance with chores. The number of financial transfers made by the grandparents as a group outweighed the amount of instrumental assistance that they received. Furthermore, it was noted that genuine dyadic exchanges were rare; instrumental assistance was provided only when it was perceived to be required, and those grandparents who received assistance tended not to be those who gave financial gifts. Here it seems that asymmetry both in and through time was the norm, and furthermore, that in many cases this asymmetry favoured the adult children.

In the US context, meanwhile, Rook [47] has argued that in the case of family, asymmetry is not only accepted, but it is expected, and that its existence is not detrimental to relationship satisfaction. In a study of widowed women, she showed that inequitable exchanges of companionship, emotional support and instrumental support were associated with less positive feelings towards friends, but, for family, a lack of reciprocity was not damaging.

A number of researchers have highlighted the differences between peer and family relationships in terms of the obligations associated with each and their different takes on reciprocity. Adams and Blieszner [1] note that the beneficial effects of friendship on the wellbeing of older people are wellestablished, and highlight the status of friendship as an achieved rather than ascribed relationship. They note too that it offers different opportunities for confiding in age-peers and participating in larger society. Fiori et al. [20] explain their 
finding that friendship is more beneficial than family for mental health by underlining the non-obligatory nature of friendship: because peers are not indebted to one another, their relationships are not associated with dependence. Rook [47] also notes the voluntary nature of friendship, observing that relationships with peers are more likely to be based on mutual interests and social needs, whereas family ties are associated with greater degrees of obligation and formality. She suggests that because friends are not compelled to provide support, their doing so is a clear expression of concern and affection, whereas the provision of support from family members comprises concern, affection, and a tinge of duty.

While Rook's [47] study suggests that asymmetry is not harmful to relationship satisfaction within families, research has shown that a lack of reciprocity is not without other consequences. For instance, recent work by Krause [36] has explored how different types of support provided to older people by their families affect their sense of 'meaning in life'. Meaning in life refers to a sense of order, coherence and purpose, incorporating the pursuit and attainment of worthwhile goals and a sense of fulfilment. Krause surveyed retired people aged 65 and over to assess their experience of meaning in life, along with their perceived receipt of different types of support. These comprised emotional support (e.g. talking through problems), tangible support (e.g. doing the shopping), informational support (i.e. providing information), and anticipated support, described as the elder's confidence that help will be received if needed. Both emotional and anticipated support were associated with greater meaning in life, while informational support was found to have no discernible effect. But most interesting for the current discussion was the finding that tangible support was associated with less meaning in life. Krause suggests that the inability to reciprocate has implications for the self-concept of older people, by resulting in a sense of dependency, or implying incompetence.

These findings are not the first to indicate that a lack of reciprocity can have negative effects on older people. Keyes [34] has also demonstrated that unequal exchanges of emotional support are disadvantageous for the emotional wellbeing of older adults (in this case aged 55 to 74), but again, that the direction of exchange is a determining factor in how these effects were realised. Elders who gave more support than they received had similar levels of wellbeing to those who had equal exchanges, whereas those who received more than they gave reported less positive and more negative affect. Like Krause [36], Keyes points to the possibility that support could create a sense of dependency, and notes that giving support can generate a source of purpose in life, even if it is not reciprocated.

Evidence such as this complements an argument put forward by Antonucci [3], who suggests that social relationships are of particular importance because they affect elders' sense of control. Citing previous work, which shows that perceived support is more consequential for the health of older people than actual support (e.g., [5]), she proposes that it is essential to consider how social situations are interpreted if we are to understand how their benefits are realised. Factors such as selfesteem and self-efficacy are relevant here, both of which have been shown to be related to health, and both of which are influenced by social support. Antonucci and Jackson [4] have suggested that self-efficacy in particular plays a mediating role in the relationship between provision of support and health. In their support-efficacy model, they suggest that providing support in such a way that the receiver continues to see themselves as able and worthy allows that individual to maintain a high level of self-efficacy. This affects the ways in which daily challenges are faced and dealt with, as well as having obvious consequences for self-esteem. Furthermore, these effects may be positively reinforcing; Antonucci [3] cites findings from Dras et al. [17], who found self esteem to the best predictor of perceived, or subjective, support.

\subsection{Autonomy and Dignity}

The findings in the previous section are to some extent contradictory; on the one hand evidence suggests that the inability to reciprocate is damaging to one's self-image, while on the other, research shows that asymmetry in family relationships is perfectly acceptable. One way of drawing these findings together is to suggest that while a lack of reciprocity is unlikely to damage family ties, it nevertheless has consequences for the ways in which elders see themselves.

Rook [47] examined the effects of receiving various types of support on satisfaction with the social relationship in question, in contrast to Krause's [36] study which used the broader measure of meaning in life. While the provision of unneeded tangible support might not weaken relationships with particular family members, it may still affect feelings of self-worth. It seems clear that reciprocity is not the only issue here; the maintenance of autonomy, and the sense of dignity that is associated with it, are also relevant. Themes relating to autonomy were evident in much of the research described in the previous section, demonstrating the extent to which reciprocity and autonomy are intertwined. However, it is worth extending the discussion of independence to focus on research that has addressed this topic in more depth.

The importance of autonomy to older people, and their reluctance to feel as though they rely on family members, is clearly demonstrable in focus group findings reported by Spitze and Gallant [51]. The elders that were interviewed here were so keen to emphasise their independence that it was difficult for the researchers to explore ways in which they did receive help:

"(M: Can you tell us in what way do members of your family help you take care of yourself?)

(\#s 1, 5, 9, women all together): No

(M: Does anyone in your life make it easier for you to take care of yourselves?)

(\#s 14, 37, 47, women): No.

Definitely not.

I think all of us live alone." (p. 394)

One of the recurring themes in Spitze and Gallant's findings is their participants' sense of their adult children being overprotective. This resulted in some of them withholding information from their offspring to avoid causing concern and others telling their children that they were being too intrusive. Some also reported preferring to confide in friends, not only because they could bring a peer's perspective to a situation, but because this was a way of maintaining their own autonomy and guarding against the possibility of their children interfering.

The impression suggested from these findings is that older people do not wish to tap into a support bank constructed on the back of care they have provided to their own children. Instead it seems that they wish to avoid being on the receiving end of support, and to continue to live autonomously and without interference from their offspring. It is possible that van Tilburg et al.'s [52] Italian elders, who live with their families out of tradition rather than necessity, would express a similar sentiment.

\subsection{Renegotiating Responsibilities}

Implicit in the above is the reaction of older people to a shifting of family roles. Where the parents once were the providers of 
help and support, they increasingly find themselves on the receiving end of it. It is worth noting that elders are not alone in this renegotiation of responsibilities; the adult children concerned also need to reassess the relationship. Schwartz et al. [49] have investigated intergenerational relationship quality, and how this is affected by exchanges of support, from the perspective of adult daughters. A lack of balance was associated with a lower quality of relationship between daughter and mother, but only when the perceived asymmetry was in the direction of the daughter giving more. Citing Blenkner [8], Schwartz et al. speculate that this may be due to difficulties in coming to terms with role changes within the relationship, whereby the adult child has to take responsibility for her parents, instead of expecting ongoing support from them. They further suggest that daughters are able to accept an imbalance in which they receive more by viewing their parents as continuing to contribute to the support bank; they consider that they will reciprocate the support in the long run. Feelings of being burdened were also found to be related to daughters' perceptions of giving more emotional support than they received. However, the findings here were somewhat contradictory; while provision of emotional support was associated with felt burden, it was also related to feelings of closeness with the mother.

Schwartz et al. [49] suggest that these paradoxical findings can be interpreted in light of a framework of ambivalence, originally put forward by Lüscher and Pillemer [41]. They suggest that relationships among kin are characterised by conflicting emotions, which simultaneously incorporate affection and resentment, willingness to help and a sense of obligation or being burdened. Lüscher and Pillemer suggest that relationships with elderly parents are underlined by contradictory norms: adults strive for self-reliance, but as we have already noted, dependence across generations is typical. Furthermore, norms relating to reciprocity suggest that relationships should not be unduly asymmetrical, but adult children are expected to offer help to close relatives wherever it is needed. While these proposals have not received unequivocal support (see e.g., [40]), it is clear that there is room in family relationships for a multitude of emotions which, superficially at least, appear to be at odds with one another.

Returning to the viewpoint of elders, the findings from Spitze and Gallant's [51] focus groups, described above, were also interpreted using Lüscher and Pillemer's [41] framework. While it is clear that elders do wish to maintain their autonomy and discourage overprotectiveness in their children, they are simultaneously reassured by the notion that their offspring will be available to provide support should it be needed. A lack of availability would also violate role expectations. Spitze and Gallant noted that elders who suffered such a lack tended to make excuses for their children, for example, by highlighting the importance and time-consuming nature of their careers.

\subsection{Summary}

Three intertwined themes have been highlighted in this overview of the gerontology literature: reciprocity, autonomy and the renegotiation of roles and responsibilities. It has been suggested that elders are most motivated to engage in relationships that are emotionally meaningful to them, and that because of this they are likely to invest in family ties. However, the nature of these relationships can have important, and occasionally negative, consequences for feelings of self-worth. In particular, the non-reciprocal nature of family relationships has been highlighted, and the implications of this for selfconcept demonstrated. Surprisingly, a lack of reciprocity that favours the adult child appears to be the best option for all involved, with older people wishing to maintain their autonomy and with both parties finding shifts in role expectations challenging. However, it is obviously also important that older people receive the support they require. Ideally, they should be able to obtain this through their social relationships, while maintaining a sense of being valued, competent and needed. Adams and Blieszner [1] summarise the argument by suggesting that 'ageing well' is best supported when families provide opportunities for their elderly relatives to contribute, but also offer assistance when it is required.

\section{THEMES FROM HCI}

The development of technologies for elders in the fields of human factors and HCI has been motivated by a number of issues. Researchers have attempted to address problems associated with cognitive decline, they have considered ways of integrating older people into the wider community, and they have attempted to reinforce social connections and emotional ties. They have also argued for universal design, which should be of benefit to a wider range of users. Though the aim of this review is to focus on older people as a social and moral category, and not one defined by physical and cognitive decline, much of the HCI and human factors literature does look at older people in this way. We shall therefore review this research as well, especially where it has implications for relationships and social connections.

As in the previous section, a number of themes can be drawn from the literature, with technologies being developed to offer reassurance, to support intimacy, to encourage reciprocity and to broaden roles. Evidently, these themes have a degree of overlap with those drawn from the gerontology literature, and the lack of reciprocity that has already been noted can be observed again in studies that have attempted to support links between family members. While researchers have managed to encourage reciprocity through activities such as play, they have tended to look outside of the family when aiming to create mutual roles for older people.

\subsection{Independence and Reassurance}

Research in the fields of HCI and human factors has long incorporated the idea of supporting 'ageing in place' in the face of cognitive and physical decline. In a 1990 review of the human factors literature, Smith [50] highlighted two conceptual frameworks that were driving the field at that time. The first (cf. [38]) focuses on the physical and psychological impairments that come with age, with the aim of minimising their impact through alterations to the environment. The second (cf. [23]) takes as its starting point life-span models of development, which incorporate a view of ageing as offering constancy (i.e. a continuation of roles at work and at home), positive adaptation, and growth, as well as recognising the reality of loss. Smith contends that it is necessary to accommodate growth as well as decline, and to be sensitive to social and psychological needs as well as those relating to performance. However, the research that he reviews largely aims to support constancy, at work, at home, and in terms of mobility, rather than enabling development. It seems that the field has become broader since Smith's review, with recent research demonstrating attempts to go beyond designing for the continuation of one's current lifestyle into old age. Additionally, researchers have widened their focus from the development of technologies that support ageing in place to a consideration of what the social implications of these devices are. However, assisting ageing in place remains a significant research goal, and one that has been buoyed up by findings from the relatively recent adoption of methodologies such as ethnography. 
Ethnographic studies of older people carried out in the context of deriving design requirements have tended to echo the gerontology literature in emphasising the importance of independence to elders. Hirsch et al. [28] have suggested that autonomy, along with engagement with others, is a major contributing factor to quality of life in old age. Similarly, Forlizzi et al. [22] have noted the importance of maintaining independence and of not becoming "a burden" to offspring. Thus the idea of supporting independence through ageing in place continues to be a prevalent theme in design, and has been spurred on by recent advances in ubiquitous computing and artificial intelligence. These developments have made obvious contributions in research on monitoring technologies in particular.

One of the attractions of using technology to monitor older people is that it has the potential to support continuing independence without requiring explicit intrusion into the lives of their adult children. Advances in research have demonstrated possibilities for monitoring life rhythms or important events such as the taking of medication, allowing behavioural changes to be noted and alarms raised where these indicate cause for concern. Activity can be assessed by embedding sensors into furniture (e.g., [32]), by creating RFID and sensor networks within the home (e.g., [27, 29]), and even by monitoring water usage [21]. However, it is often not clear where the data generated by these sensors will end up, or whether elders themselves will have access to it. In some cases, steps are taken to enable older people to retrieve the information that is collected about them. Ballegaard et al.'s Roberta [6] is one example of this; here data regarding the taking of medication was made accessible to both caregivers and the elders who were in receipt of care. However, even here problems with the technology undermined efforts to support access to the information gathered. A field trial highlighted the fact that difficulties experienced by the elders in using a tablet PC were sufficient to minimise their interactions with it: one participant's attempt to 'customise' their tablet involved placing it under a doily and vase in their home. In many other attempts to support monitoring, the notion of data being presented to carers and family members is implicit, but the repercussions of doing so are rarely discussed.

Clearly there are issues here surrounding what the information derived from monitoring technologies will be used for, and how this might infringe on the rights of the people that they are designed to help. It could be argued that failing to allow access to this data would work against the very notion of independence that they are designed to support. Similar concerns have been raised by Blythe et al. [9], who put forward an argument for socially dependable design. They suggest that if technologies are to be accepted by older people, they need to fit the social context of the home (placing a PC under a doily can be seen as an effort of trying to achieve this) and to be designed with their effects on social relationships in mind. They observe that monitoring systems that are stigmatising are unlikely to be adopted (see also [28]) and that personal triggers must not induce feelings of lost independence if they are to be worn. They also raise the issue of informed choice, suggesting that while lifestyle monitoring systems allow for less intrusive observations, they also raise important social issues regarding privacy and informed consent.

Some researchers have explicitly examined the role of family in monitoring technologies, using relatives to interpret the data gathered rather than relying on artificial intelligence. A prominent example of this is the Digital Family Portrait (DFP, [44]), a picture frame designed to be placed in the home of an adult child, containing a photograph of their elderly parent. The frame displays information gathered from sensors in the parent's house: icons around the border represent activity levels for the most recent 28 days, and touching the icon for a specific day reveals movement patterns within the home along with contextual information such as the weather. Rowan and Mynatt [48] suggest that the DFP might be used to support peace of mind for elders' relatives, and derive some evidence for this from a field trial of the technology. Sensors were installed in the home of an active 76 year old woman, with the frame placed in the home of her adult son. The DFP was well accepted by the two family members, and allowed the son to maintain a level of awareness of his mother which felt nonintrusive to them both but that enabled him to detect irregularities in her routine. Devices such as these can build on the knowledge that family members have of one another, providing reassurance that everything is as it should be (see also [11] for similar findings from a study of cohabiting families).

Rowan and Mynatt [48] acknowledge that the use of sensorbased communications could result in adult children relying on these too heavily to maintain emotional connections with their parents, a possibility also highlighted by Blythe et al. [9]. Additionally, Hirsch et al. [28] use the findings of their ethnography to argue that the balance between autonomy and engagement with others is crucial; an elderly person who is highly socially engaged but feels infantilised due to a lack of autonomy is as disadvantaged as someone who is at risk of becoming socially isolated but remains highly independent. It should be noted that Rowan and Mynatt found no evidence of their family becoming overly reliant on the DFP for sustaining intimacy; feelings of connectedness and communication patterns showed no changes when the DFP was installed or after it was removed, either for better or for worse. However, the family in this study did have high feelings of connectedness in general (in fact, for the son these were approaching ceiling level), and it would be of interest to see if the findings will generalise to relatives who are less attached.

\subsection{Intimacy and Asymmetry}

Other researchers have explored issues of engagement and intimacy directly, using technology to foster lightweight connections between remote family members as opposed to supporting one-way links. The aim here is often to bring about feelings of shared presence, described as tsunagari-kan, or a sense of closeness to others, by Miyajima et al. [42]. In a field trial of the FamilyPlanter (FP), first described by Itoh et al. [33], Miyajima et al. explore the extent to which thoughts about remote others can be evoked through ambient signals, and whether this can elicit feelings of familiarity and fellowship. FPs are paired devices that support communication across two households. They convey information through optical fibres, which glow to indicate presence and rotate to indicate motion. More deliberate attempts to communicate can be achieved through touches to the base, which result in the paired FP emitting sounds. The system was evaluated in Japan, with three families in which elderly members lived in separate accommodation (as well as one with a college student living away from home) over a three-month period. Most participants derived some relief from the motion signals displayed by the planter, and found the touch signals to be enjoyable. However, the older family members were found to have much more positive feelings about the planter than their adult children did, taking comfort from the sense of presence that it provided. Miyajima et al. note that this diverges from the idea of using technology as a way of providing reassurance to the adult children of elders. However, it is not an isolated example; work undertaken in the US [45] reveals a similar finding. 
Through their study of a shared family calendar, Plaisant et al. [45] aimed to promote a symmetrical exchange of information while facilitating coordination and awareness. They deployed the calendar with an extended family comprising a young family and their two sets of grandparents. Again, the calendar was partially motivated as being a way of allowing adult children to see whether their parents' activity levels were normal or not, presumably to provide a degree of reassurance and to act as a way of highlighting problems. However, the main finding was that both sets of grandparents took pleasure in being able to see the schedules of the younger family: they described checking the calendar on a daily basis and were disappointed when it was taken away. In contrast, the younger family reported that they liked knowing the grandparents could follow what was going on in their own lives, but they felt that they were too busy to check the calendars themselves, that they already knew what their grandparents were up to, and that "nothing too exciting had happened" in the lives of their grandparents during the field trial to motivate more regular inspections. The family that was studied lived close together and had a good deal of contact via the telephone, perhaps making the calendar less needed than it might be for kin who live some distance apart. Nevertheless, the findings of this study combined with those reported by Miyajima et al. [42] suggest that elders often show more interest in the activities of their adult children than vice versa.

Other researchers have tried to increase more social interaction between elders and their friends or family by encouraging the older people involved to take more direct action. Morris [43] has used technology to depict the social networks of elders as solar systems, with friends and family shown as planetary representations that move towards the periphery as contact decreases. The design was intended to encourage selfreflection, and did indeed act as a motivating factor for elders to initiate contact with people they were losing touch with.

To summarise so far, the young relatives of older people are often thought of as a group who might derive peace of mind through monitoring technologies, which are also seen as aids to autonomy. However, research has demonstrated that elders seem to be more interested in the goings-on of their children than vice versa, and even where researchers design with the explicit aim of supporting symmetry, asymmetry tends to be the result. Successful attempts at increasing the initiation of contact and combating social isolation have also encouraged elders to take the first step in addressing their problems. Perhaps these findings are not surprising when considered in the context of the gerontology literature, which also highlighted the difficulties of finding symmetry within family relationships. However, it has not deterred some researchers from designing to encourage reciprocity in social interaction.

\subsection{Reciprocity and Play}

The concept of reciprocity emerges in two rather different contexts in research relating to older people and technology. Miyajima et al. [42] examined reciprocity as a way of characterising the nature of the filial relationships that they studied. They predicted that a lack of equilibrium would weaken the experience of tsunagari-kan derived from the FamilyPlanters that were deployed, and found some evidence to support this idea. A rather different approach is taken by researchers who attempt to explicitly encourage reciprocity, for example by supporting types of interaction that are inherently symmetrical in nature, such as play.

Davis et al. [14] have emphasised the importance of reciprocity as a characteristic of intergenerational relationships, suggesting that this is a key area of parent-child intimacy. Building on previous work that indicated the desire of parents to have more reciprocal interactions with their young children, they developed a Virtual Box, designed explicitly to encourage this. The Virtual Box is based on the game of hide and seek; a PDA is used to find a virtual 'box', the location of which is determined by positioning technology. Parents or grandparents place content, such as pictures, text messages or video clips, within the box, and set its virtual position within the home. The PDA is then used by the child to find it and access the content. Davis et al. recognise that inequality is a necessary quality of relationships with young children, and have consequently included elements of asymmetry in their design: grandparents set up the game, while children indulge in its playful elements. It is suggested that by acknowledging this asymmetry, a degree of reciprocity might be achieved. Lab evaluations underlined the importance of reciprocity within the game; children wished to take a turn at hiding the box once they had located it, and the content created by grandparents often included questions that demanded answers. This allowed an ongoing interaction to be mediated through the technology.

While play is a common theme in supporting interactions between grandparents and grandchildren, few researchers have utilised it to support remote contact. One exception is the game of Age Invaders [35], which supports both collocated and distant play. This is a social-physical game based on the wellknown Space Invaders, enacted on a floor display on which players move, shoot bombs and dodge rockets. The parameters can be altered for different participants, allowing players with slower movements and reaction times to be compensated for. However, even here the involvement of remote players revolves around them placing bonus items or adjusting parameters, rather than being actual competitors.

A piece of research that does demonstrate the potential for reciprocal interaction at a distance is presented by Davis et al. [15]. In a study of Magic Boxes, which partly inspired the Virtual Box described above, grandparents and grandchildren were encouraged to interact with one another by placing items in a physical box. This was then transported across households by the 'Magic Box Fairy'. The boxes were used as cultural probes [25], there being no technology involved, but the findings demonstrate how intergenerational play at a distance can be supported. Davis et al. note that even here an element of asymmetry in the roles that family members played underlined their interactions. Grandparents looked for ways to provoke their grandchildren into responding, by creating simple games or activities. For example, one grandmother sent photos of family members as children, with the task of 'finding your mum'. In contrast, objects placed in the box by the grandchildren were more self-centred, drawn from their own daily activities and reflecting their role as the focus point of their grandparents' affection.

\subsection{Roles}

The role of grandparenting is inherent in much of the work presented above, with Davis and colleagues in particular taking inspiration from the idea that grandparents derive a sense of meaning from caring for grandchildren. Forlizzi et al.'s [22] ethnography, mentioned earlier, has also highlighted how important it is for older people to maintain a role within the family. In one example, an elder's need to make herself useful was so great that it was potentially detrimental:

"Mrs. G. spent most of her time at her daughter's house, providing "assistance" in buying food and preparing meals. We observed her working in her kitchen during our visit. The kitchen cupboards and the refrigerator were in a state of general disarray [...] These observations suggest that the 
relationship was more a social then a practical necessity for Mrs. G.'s daughter and grand-daughter. Mrs. G. may have been acting beyond her capabilities and possibly straining the very relationship she believed to be helping." ( $p .48)$

The difficulties in designing to support familial responsibilities are reflected in the fact that most of HCI's attempts to support roles for elders have looked outside of the family. For example, Ellis and Bruckman [19] have explored ways of providing community roles for elders by allowing children to interview them online. Their internet community, Palaver Tree Online, allowed children to interact with older people with the aim of developing oral histories. Hofmeester et al. [31] also attempted to take advantage of the wider experience and free time that older people can offer, by using technology to regenerate the role of the 'village elder'. The Presence project that this work was part of initially aimed to offer a variety of roles to older people, from 'living memory' to 'guide' to 'commentator'. Interestingly, one of the roles suggested was that of 'family member', although what this might involve is not detailed in the paper. Outputs from this project focused more on allowing ways for older people to become influential members of their communities. For example, the Projected Realities system [25], a network of displays that portrayed images and provocative statements collected and compiled by elders, was intended to assist older people in the task of inspiring their community, which was characterised by cultural diversity, in recognising a coherent expression of themselves.

When attempting to support mutual responsibilities for elders, the focus in HCI is tellingly on peer relationships. Riche and Mackay [46] have emphasised the importance of 'PeerCare' for older people, which is defined as a reciprocal care relationship between older people. The notion of PeerCare was used to inspire the development of MarkerClock, a device which offers a means of passively communicating through activity traces and of actively communicating via ambiguous symbols (for which meanings can be appropriated). The timings of both are displayed on clock faces, which can be linked across up to four elders. The design is intended to allow elders an active role in monitoring one another, as opposed to being monitored by their younger relatives or carers. It is notable that in HCI, as in the gerontology literature, mutual roles are associated with relationships between friends.

\subsection{Summary}

Research from the fields of HCI and human factors that considers the social relationships of elders can be organised into four themes: independence and reassurance, intimacy and asymmetry, reciprocity and play, and the roles that older people adopt. Once again, the asymmetrical nature of family ties, in contrast with the mutual nature of friendship, can be seen to underlie all four. While it is often assumed that the adult children of elders can derive peace of mind about their parents through technical devices, it seems apparent that older people are just as interested in deriving details about the lives of their offspring through technology, if not more so. Attempts to encourage symmetrical interactions have relied on reciprocal activities such as play, and even here success is related to an acknowledgement of the asymmetry that is inherent in family relationships. Finally, attempts to generate roles for older people have often avoided the issue of family, with attempts to design for reciprocity relying on relationships between peers.

\section{KEY FINDINGS}

This review has highlighted a number of themes within the gerontology, HCI and human factors literature, which highlight various commonalities. The notions of reciprocity and asymmetry underlie much of the research reported here, as does the concept of autonomy and the challenges associated with renegotiating roles in later life.

We find that a close reading of this literature shows that some of the more simplistic assumptions about older people simply do not hold when we consider research which explores the nature of what it means to be old, and when we look at the results of studies in which new technologies have actually been deployed. As a case in point, assumptions about loneliness and isolation seem to have been overplayed: many elderly people do live alone but are perfectly happy to do so. As another example, social connections with friends are often key to this kind of wellbeing, and having a few close friendships may be more important than having a large social network. As a third example, simple assumptions about the need for reciprocity and the support of 'two-way' relationships are not sustained. Symmetry may be important in friendships, but not so in families, where more 'give' than 'take' on the part of the elderly may be not only tolerated but preferred. This is tied up with elderly people's sense of self-worth, about not wanting to be looked after, and about being independent.

These sorts of findings have important implications for how we think about designing for older people, at least for those in Western cultures, where much of this research was carried out. For example, it suggests that technologies designed to 'look after' and 'protect' the elderly may not always appeal. In fact, they may undermine an older person's sense of self-worth and dignity. As another example, it suggests that devices designed to give older people a presence in the homes of their children, or a symmetrical connection between homes, may also not be the ideal approach. Our reading of the literature shows that the nature of the family relationship is asymmetric, suggesting older people are more likely to want to monitor and look in on their offspring, than vice versa.

Rather than to simply offer a critique, however, this deeper understanding of the literature can offer guidance and lead to new design directions. We do not offer a compendium of these directions but offer some illustrations to conclude.

First of all, the literature highlights the fact that older people are most motivated to sustain close relationships that are emotionally meaningful, rather than to forge new friendships. Therefore, when designing to bolster social connections, it is important to emphasise technologies that strengthen relationships that already exist rather than those which require initiating new ones.

Second, family relationships are not reciprocal, and this appears to be acceptable to both parents and adult children. Therefore, when designing to support intergenerational family relationships, it is worth acknowledging the existence of asymmetry. In particular, this has implications for remote presence technologies and suggests that older people may see more value in monitoring the activities of their offspring than vice versa, and that they may have more time to do so. In other words, their family relationships do not have to be a two-way street.

Third of all, asymmetry is only acceptable in certain circumstances. Notably, it can be detrimental in friendship. In terms of technology design, this suggests that technologies which connect peers rather than family do need to be sensitive to symmetry, and further that these devices probably ought to be configured differently from those designed with family ties in mind.

Fourth, it is clear that with increasing age, the balance of asymmetry will shift. The negative implications associated with this are tied in part to a loss of autonomy; elders are reluctant to 
allow their adult children to interfere in their lives, although they do appreciate their concern. In terms of technology, therefore, design needs to offer solutions which strike a delicate balance between allowing families to show they care without impinging too much in daily life. Likewise, older and more infirm people may reject technologies which invite concern and over-protectiveness. It may be better, for example, to design technologies which invite elders to initiate contact, or to provide reassurance that all is okay, thus placing control back in their own hands.

Fifth and last, as the balance of asymmetry does shift, the responsibilities of family members need to be renegotiated. Researchers in HCI have found it easiest to create roles for older people outside of the family. However, the importance of family suggests that it is worth exploring how family roles for older people might be supported. This points to a large design space where elderly people need to be supported in contributing more to family life. It may be that technologies could enable them to take on a remote role in the organisation of family life, for example by enabling connections and responsibilities with grandchildren.

\section{CONCLUSION}

This paper aimed to put forward research directions and design ideas regarding how technology might be used to support the social connections of older people, by drawing on research in the fields of gerontology, HCI and human factors. In particular, it has shown that assumptions about symmetry being inherent in family ties can be misleading; that asymmetry is often a better way of accounting for older people's attitudes to their families; and that asymmetry offers a better basis for design. It has been noted too that while lifestyle monitoring may provide peace of mind to adult children, and devices supporting presence at a distance are often embraced by elders, new technologies may be at their most effective when they allow older people to actively contribute to the lives of those who are important to them. By allowing this group to maintain a role within the family and to return the help that they do receive, design can allow older people to preserve their sense of self-worth. Being old is not just a physical fact in other words; it is also a social status that older people seek to manage, sometimes resisting, sometimes accepting. The most important lesson from our reading of the literature is this conundrum: one we will all, eventually, have to deal with.

\section{REFERENCES}

[1] Adams, R.G. and Blieszner, R. Aging well with friends and family, American Behavioural Scientist, 39, 2 (November/December 1995), 209-224.

[2] Antonucci, T.C. Personal characteristics, social support, and social behavior. In R.H. Binstock and E. Shanas (Eds.), Handbook of aging and the social sciences, Van Nostrand Reinhold (1985), 94-128.

[3] Antonucci, T.C. Social relations: An examination of social networks, social support and sense of control. In J.E. Birren and K.W. Schaie (Eds.), Handbook of the Psychology of Aging, Academic Press (2001), 427-453.

[4] Antonucci, T.C. and Jackson, J.S. Social support, interpersonal efficacy and health. In L.L. Carstensen and B.A. Edelstein (Eds.), Handbook of clinical gerontology, Pergamon Press (1987), 291-311.

[5] Antonucci, T.C., Fuhrer, R. and Dartiques, J.F. Social relations and depressive symptomatology in a sample of community-dwelling French older adults. Psychology and Aging, 12, (1997), 189-195.
[6] Ballegaard, S.A., Bunde-Pedersen, J. and Bardram, J.E. Where to, Roberta? Reflecting on the role of technology in assisted living. In Proc. NordiCHI '06, ACM Press (2006), 373-376.

[7] Bengston, V.L. and Roberts, R.E.L. Intergenerational solidarity in aging families: An example of formal theory construction. Journal of Marriage and the Family, 53, (November 1991), 856-870.

[8] Blenkner, M. Social work and family relationships in later life with some thoughts on filial maturity. In E. Shanas and G.F. Streib (Eds.), Social structure and the family: Generational relations, Prentice Hall (1965), 46-59.

[9] Blythe, M.A., Monk, A.F. and Doughty, K. Socially dependable design: The challenge of ageing populations for HCI. Interacting with Computers, 17, (2005), 672-689.

[10] Borglin, G., Edberg, A. and Hallberg, I.R. The experience of quality of life among older people. Journal of Aging Studies, 19, (2005), 201-220.

[11] Brown, B., Taylor, A.S., Izadi, S., Sellen, A., Kay, J.J. and Eardley, R. Locating family values: A field trial of the Whereabouts Clock, In Proc. UbiComp '07, ACM Press (2007), 354-371.

[12] Carstensen, L.L., Fung, H.H. and Charles, S.T. Socioemotional selectivity theory and the regulation of emotion in the second half of life. Motivation and Emotion, 27, 2 (2003), 103-123.

[13] Carstensen, L.L., Gross, J.J. and Fung, H.H. The social context of emotional experience. In K.W. Schaie and M.P. Lawton (Eds.), Annual review of gerontology and geriatrics: Vol 17, Springer (1997), 325-352.

[14] Davis, H., Skov, M.B., Stougaard, M. and Vetere, F. Virtual Box: Supporting mediated family intimacy through virtual and physical play. In Proc. $\mathrm{OzCHI}$ '07, ACM Press (2007), 151-159.

[15] Davis, H., Vetere, F., Francis, P. Gibbs, M. and Howard, S. "I wish we could get together": Exploring intergenerational play across a distance via a 'Magic Box', Journal of Intergenerational Relationships, (in press).

[16] Degnen, C. Minding the gap: The construction of old age and oldness amongst peers. Journal of Aging Studies, 21, (2007), 69-80.

[17] Dras, D., Williams, R.B., Kaplan, B.H. and Siegler, I.C. Correlates of perceived social support and equality of interpersonal relationships at mid-life. International Journal of Aging and Human Development, 43, (1996), 199-217.

[18] Due, P., Holstein, B., Lund, R., Modvig, J. and Ablund, K. Social relations: Network, support and relational strain. Social Science and Medicine, 48, (1999), 661-673.

[19] Ellis, J.B. and Bruckman, A.S. Designing Palaver Tree Online: Supporting social roles in a community of oral history. In Proc. SIGCHI '01, ACM Press (2001), 474481.

[20] Fiori, K.L., Antonucci, T.C. and Cortina, K.S. Social network typologies and mental health among older adults. The Journal of Gerontology: Psychological Sciences, 61B, 1 (2006), P25-P32.

[21] Fogarty, J., Au, C. and Hudson, S.E. Sensing from the basement: A feasibility study of unobtrusive and low-cost home activity recognition. In Proc. UIST '06, ACM Press (2006), 91-100. 
[22] Forlizzi, J., DiSalvo, C. and Gemperle, F. Assistive robotics and an ecology of elders living independently in their own homes. Human-Computer Interaction, 19, (2004), 25-59.

[23] Fozard, J.L. Person-environment relationships in adulthood: Implications for human factors engineering. Human Factors, 23, (1981), 7-27.

[24] Gabriel, Z. and Bowling, A. Quality of life in old age from the perspectives of older people. In A. Walker and C.H. Hennessy (Eds.), Growing older: Quality of life in old age, Open University Press (2004), 14-34.

[25] Gaver, W. and Dunne, A. Projected realities: Conceptual design for cultural effect. In Proc. CHI '99, ACM Press (1999), 600-607.

[26] Gouldner, A.W. The norm of reciprocity: A preliminary statement. American Sociological Review, 25, (1960), 161 178.

[27] Haigh, K.Z., Phelps, J. and Geib, C.W. An open agent architecture for assisting elder independence. In Proc. AAMAS '02, ACM Press (2002), 578-586.

[28] Hirsch, T., Forlizzi, J., Hyder, E., Goetz, J., Stroback, J. and Kurtz, C. The ELDer project: Social, emotional, and environmental factors in the design of eldercare technologies. In Proc. CHI '00, ACM Press (2000), 72-79.

[29] Ho, L., Moh, M., Walker, Z., Hamada, T. and Su, C-F. A prototype on RFID and sensor networks for elder healthcare: Progress report. In Proc. SIGCOMM '05 Workshop, ACM Press (2005), 70-75.

[30] Hoff, A. Patterns of intergenerational support in grandparent-grandchild and parent-child relationships in Germany. Ageing and Society, 27, (2007), 643-663.

[31] Hofmeester, K., Dunne, A., Gaver, B., Susani, M. and Pacenti, E. A modern role for the village elders. Ext. Abstracts CHI '99, ACM Press (1999), 43-44.

[32] Hurst, A., Zimmerman, J., Atkeson, C. and Forlizzi, J. The Sense Lounger: Establishing a ubicomp beachhead in elders' homes. Ext. Abstracts CHI '05, ACM Press (2005), $1467-1470$

[33] Itoh, Y., Miyajima, A. and Watanabe, T. 'Tsunagari' communication: Fostering a feeling of connection between family members. In Proc. CHI '02, ACM Press (2002), 810-811.

[34] Keyes, C.L.M. The exchange of emotional support with age and its relationship with emotional well-being by age. The Journal of Gerontology: Psychological Sciences, 57B, 6 (2002), P518-P525.

[35] Khoo, E.T., Lee, S.P., Cheok, A.D., Kodagoda, S., Zhou, Y. and Toh, G.S. Age Invaders: Social and physical intergenerational family entertainment. In Proc. CHI '06, ACM Press (2006), 72-79.

[36] Krause, N. Longitudinal study of social support and meaning in life. Psychology and Aging, 22, 3 (2007), 456469.

[37] Laslett, P. A fresh map of life: The emergence of the third age. Harvard University Press (1991).

[38] Lawton, M.P. Competence, environmental press, and the adaption of older people. In M.P. Lawton, P.G. Windley and T.O. Byerts (Eds.), Aging and the environment: Theoretical approaches, Springer (1982), 33-59.

[39] Lee, D.J. and Markides, K.S. Activity and mortality among aged persons over an eight-year period. The Journal of Gerontology: Social Sciences, 45, (1990), S39-S42.

[40] Lowenstein, A. Solidarity-conflict and ambivalence: Testing two conceptual frameworks and their impact on quality of life for older family members. The Journal of Gerontology: Social Sciences, 62B, (2007), S100-S107.

[41] Lüscher, K. and Pillemer, K. Intergenerational ambivalence: A new approach to the study of parent-child relations in later life. Journal of Marriage and the Family, 60, 2 (May 1998), 413-425.

[42] Miyajima, A., Itoh, Y., Itoh, M. and Watanabe, T. "Tsunagari-kan" communication: Design of a new telecommunication environment and a field test with family members living apart. International Journal of Human-Computer Interaction, 19, 2 (2005), 253-276.

[43] Morris, M.E. Social networks as health feedback displays. IEE Internet Computing, 9, 5 (September/October 2005), 29-37.

[44] Mynatt, E.D., Essa, I. and Rogers, W. Increasing the opportunities for aging in place. In Proc. $C U U^{\prime} 00$, ACM Press (2000), 65-71.

[45] Plaisant, C., Clamage, A., Browne Hutchinson, H., Bederson, B.B. and Druin, A. Shared family calendars: Promoting symmetry and accessibility. ACM Transactions on Computer-Human Interaction, 13, 3 (2006), 313-346.

[46] Riche, Y. and Mackey, W. MarkerClock: A communicating augmented clock for elderly. In Proc. Interact '07, Springer (2007), 408-411.

[47] Rook, K.S. Reciprocity of social exchange and social satisfaction among older women. Journal of Personality and Social Psychology, 52, 1 (1987), 145-154.

[48] Rowan, J. and Mynatt, E.D. Digital family portrait field trial: Support for aging in place. In Proc. CHI '05, ACM Press (2005), 521-530.

[49] Schwarz, B., Trommsdorff, G. Albert, I. and Mayer, B. Adult parent-child relationships: Relationship quality, support, and reciprocity. Applied Psychology: An International Review, 54, 3 (2005), 396-417.

[50] Smith, D.B.D. Human factors and aging: An overview of research needs and application opportunities. Human Factors, 32, 5 (1990), 509-526.

[51] Spitze, G. and Gallant, M.P. "The bitter with the sweet": Older adults' strategies for handling ambivalence in relations with their adult children. Research on Aging, 26, 4 (July 2004), 387-412.

[52] van Tilburg, T., Gierveld, J., Lecchini, L. and Marsiglia, D. Social integration and loneliness: A comparative study among older adults in the Netherlands and Tuscany, Italy. Journal of Social and Personal Relationships, 15, (1998), 740-754.

[53] Victor, C.R., Scambler, S.J., Bond, J. and Bowling, A. Loneliness in later life. In A. Walker and C.H. Hennessy (Eds.), Growing older: Quality of life in old age, Open University Press (2004), 107-126. 